\title{
Is childhood asthma being underdiagnosed and undertreated?
}

\author{
A N P SPEIGHT
}

British Medical fournal, 1978, 2, 331-332

\section{Summary and conclusions}

Thirty-four cases of asthma in children referred to outpatient clinics in Newcastle upon Tyne (16 cases) and London (18 cases) were reviewed. In both cities there was evidence of inappropriate diagnosis and treatment by general practitioners. One of the main factors seemed to be doctors' reluctance to use the word "asthma," even when a history of episodic wheezing strongly suggested the diagnosis.

Freer use of the word "asthma" might help parents to co-operate in managing asthmatic children and allow them to be better prepared to cope with severe asthmatic attacks if they occur.

\section{Introduction}

From my work in a paediatric department I gained the impression that childhood asthma is being clinically underdiagnosed and undertreated. Accordingly I made a survey of unselected cases of asthma referred to a general paediatric clinic in Newcastle upon Tyne. A similar survey was conducted in London.

\section{Patients and methods}

All 16 cases of asthma referred to a general paediatric clinic in Newcastle General Hospital over 12 months were included in the study. Eighteen additional cases were selected at random from general medical outpatient referrals to Great Ormond Street Hospital, London. The age range of the 34 children was 2-12 years. In both groups asthma was diagnosed clinically from a history of episodic wheezing. Information on the mode and timing of referral, length of history, and severity of previous disability was obtained from the case notes. The general practitioner's diagnosis in his letter of referral and previous drug treatment were noted. The nature of hospital treatment and the clinical response were observed.

\section{Results}

Thirty-four cases of asthma in children aged 2 to 12 years were studied retrospectively. Sixteen were from Newcastle and 18 from London.

Mode of referral-Thirty-two of the 34 children were referred by their general practitioners for specialist opinion. One was referred by

Children's Department, Newcastle General Hospital, Newcastle upon Tyne NE4 6BE

A N P SPEIGHT, MRCP, DCH, senior registrar in paediatrics a school doctor and another by the casualty department after attending for a complaint unrelated to asthma.

Length of history before referral-Twenty children had had symptoms for over two years; 13 of these had had symptoms for over four years.

Disability before referral-Nearly half of the children (15 out of 34) had missed more than six weeks of school (or nursery) in the previous 12 months because of asthma, and five had missed more than three months. Nevertheless, many children had had severe nocturnal asthma without missing much school. Others had low-grade continuous wheezing that did not prevent them from attending school, but prevented them from participating in sports. Several children had had asthmatic attacks which may have been severe enough to warrant admission to hospital.

Referral diagnosis-The word "asthma" was mentioned in the general practitioner's letter in only six out of 32 cases. The terms "wheezy bronchitis," "wheezing," or "bronchospasm" were used in 11 letters, but were not mentioned in a further 12, in which "recurrent chest infections," "recurrent cough," or "bronchitis" were given as diagnoses. Three cases were referred as cardiac problems because of exertional dyspnoea.

Main management before referral-Only two out of 34 families had been given a definite diagnosis of asthma before the child's referral. Several families had been advised about house dust and pets without being told their child had asthma. Only 14 children had received treatment with bronchodilators, and few of these had been given a supply for emergency use. Only two children had been given sodium cromoglycate, and in each case it had been discarded without proper trial, having been prescribed for symptomatic treatment only. Eighteen children had received neither bronchodilators nor sodium cromoglycate before referral, but had usually been treated with antibiotics and cough mixtures.

Hospit al management-All the parents were given an unequivocal diagnosis of asthma and an appropriate explanation. Many parents were relieved because a cause had been found for their child's symptoms. Thirteen children received intermittent treatment with bronchodilators only, and were given a supply for emergency use. Twenty of the 34 were thought to have clear indications for a trial of continuous treatment with sodium cromoglycate. Sixteen responded well, but treatment was changed to a steroid inhaler in the remaining four cases. Two children received continuous treatment with highdose choline theophyllinate.

Clinical response-Most children showed appreciable clinical improvement. The most important single factor in this improvement seemed to be treatment with sodium cromoglycate.

\section{Case history}

The following case report exemplifies some of the points raised in the study.

A 10-year-old girl was referred by her general practitioner, who wrote: "This girl has suffered recurrent bronchitis since babyhood, with attacks every six weeks. These settle with Ledermycin [demeclocycline] and Ventolin [salbutamol]. I was wondering whether there might be an allergic element to her wheezy bronchitis." In fact her history clearly showed that her asthma became worse, on exposure to dogs and horses, and she had had several quite severe asthmatic attacks. A doctor who saw one of these attacks suggested asthma as a diagnosis, but this had failed to alter the management. She had missed six months of school in the year before referral. After 
treatment with sodium cromoglycate had been begun she missed no school for 12 months.

A case reported elsewhere ${ }^{1}$ shows many parallel features. A 13-yearold boy with quite a long history of wheeze was given ampicillin but no bronchodilator by the trainee general practitioner, who was reluctant to confirm the mother's suggestion that her son had asthma.

\section{Discussion}

This survey shows that childhood asthma tends to be both underdiagnosed and undertreated by general practitioners in the areas studied. If these findings are representative of the rest of Britain they suggest that a major problem exists. Some cases of asthma present diagnostic problems-for example, when a child has a persistent nocturnal cough but no wheeze, or becomes unduly breathless and coughs after exercise. Nevertheless, most cases can be confidently diagnosed on clinical grounds on the simple basis of a history of episodic wheezing.

The following factors seem to be important in "blocking" the diagnosis of asthma.

Parents' choice of symptoms-Often the child is seen after recovery from an attack. The mother complains only of the child's "cough" and "chestiness." Only leading questions about wheezing and dyspnoea will suggest the diagnosis of asthma.

Overemphasis on the role of infection-Although many asthmatic attacks are triggered by virus infections, they are too often labelled as "chest infections" or "bronchitis." These diagnoses lead to inappropriate treatment with antibiotics and cough mixtures.

Reluctance to use the word "asthma"-This seems to be an important factor, and is understandable as historical legacy from the '50s and '60s. During these years hospital paediatricians taught a whole generation of doctors to avoid using the word "asthma" when talking to parents, as it caused unnecessary upset by suggesting a crippling and potentially fatal disease. People also believed that "wheezy bronchitis" was a different condition with a more benign prognosis. Since then Williams and $\mathrm{McNicol}^{2}$ have shown that the two conditions cannot be clearly distinguished. They showed that patients with both complaints belong to a single population with a genetically determined predisposition to disease that varies in severity and has differing precipitating factors. The clinical management of these two groups is the same. Accordingly it could be argued that the term "wheezy bronchitis" has outlived its usefulness, especially since its use as a euphemism for asthma may be a factor in denying patients access to the newer forms of treatment.

Two further points are worth considering as strong arguments for free use of the word "asthma." Firstly, if the child has moderate or severe asthma the parents must know the diagnosis to co-operate in management. Secondly, even a patient with mild asthma may suffer a severe attack at any time. Parents need to be educated about what action to take if this occurs.

I thank Dr E N Hey for his encouragement and help in analysing his own cases at Great Ormond Street, and Professor J K G Webb and Dr A Brewis for helpful discussion and advice.

\section{References}

${ }^{1}$ Mourin, K A O, and Collins, J, British Medical fournal, 1976, 2, 1003.

${ }^{2}$ Williams, H, and McNicol, K N, British Medical fournal, 1969, 4, 321.

(Accepted 10 April 1.978)

\section{MATERIA NON MEDICA}

\section{The Big Ben}

My grandfather climbed Ben Nevis when he was 66 and boasted about it for the next 20 years. My father did the ritual ascent with me in my school certificate year, and I went again when our first born was 14 The two youngest are now 12 and 13 and of two things I was certain that my next ascent of Ben Nevis would be my last, and I would not go up the tourist route.

The chosen route started up Glen Nevis, which must surely be the most under-rated glen in Scotland, its 12-mile length containing the whole range of glen scenery. From the car park at the road end, a mile or so of path through the gorge leads to the river meadows by Steall Cottage and waterfall, a most delectable spot with only the Highland midges to put vileness in the camper's prospect. Beyond, the glen opens out and after a mile or so a burn leads upwards and northwards to the col to the east of Carn Mor Dearg, the start of a most delightful ridge walk of some two miles at over 3500 feet. This includes the summit of Carn Mor Dearg, and the arête leading from it to the summit of Ben Nevis is the equal of any ridge in the country, the Coulin ridge excepted. The outlook is tremendous, and in view the whole way is the goal itself-the snow-covered summit of Ben Nevis, with its cairn and observatory ruins crowning the magnificence of its great north-eastern corries. The final treat was found on the summit plateau: a cock snow bunting chirping its heart out. The AA/Readers Digest Birds of Britain claims that there are only five nesting pairs in Britain each summer, the last recorded nest on Ben Nevis being in 1954.

Snow bunting apart, the summit of Ben Nevis was dreich and grey as usual, with the debris that any highest point attracts: forlorn memorials, orange peel and tins, a vandalised indicator, and the prospect of the descent down the tourist track. The original builders of the summit observatory in the 1880 s included a beautifully graded pony track, once fit for a Model T Ford or an Austin 7 but now largely neglected by the hordes of visitors padding their way up the Big Ben, who have taken short cuts and worn new and ever-growing scars across the hillside. By this poor track we descended, over debris and boulders, dusty, weary, and leg worn.

But that arête: I might just try it again, if I am not too elderly a grandfather when the time arrives.-G A L BINNIE (general practitioner, Berwick upon Tweed).

\section{Holiday reading}

Before a short holiday, I used to choose two or three books from my collection, often at the last moment, against a rainy day and for the late night's silent hours. I no longer do this. There is much more pleasure in sorting through the bookshops, market barrows, or the odds and ends of the places you are visiting. The idleness of browsing is refreshment in itself and there is adventure in selecting from an unknown and motley library. Bad taste, good taste, wayward or obsessional interests can be indulged and one is obliged to read what one finds; this is a browser's rule. Holiday reading consequently becomes distinctive and set apart from the psychopathology of everyday life, and, like the holiday itself, is different.

In this way, one is more likely to read disparately. For example Milton's Paradise Lost, Sir Ernest Gower's Plain Words, and Sherwood Taylor's The Century of Science filled just a short space of borrowed time, at $90 \mathrm{p}$ for the three. There is also a collector's joy in the discovery of a simple bargain-a Biennial Retrospect of Medicine and Surgery from the New Sydenham Society, MDCCCLXXI, bought on a grey Saturday afternoon in a Bethesda shop, containing 1869 references to a transient ischaemic attack, optic neuritis, and the dependance of epileptic insanity on sexual excess.

The pursuit of holiday books has hidden delights. Margin comments displaying the character and bias of a previous owner, heavy underlining, pressed flowers, or a cracked oak leaf; a dedication between friends in the dated fly leaf. These are a shared privacy from one age to the next, but buried question marks for those who enjoy reading between the lines.

Such collections bridge the generation gaps. As old houses are cleared of their contents, these small libraries come to rest in out of the way corners. They lodge the literary quandaries and tastes of over half a century ago. To the vagrant intellectual, they are islands of enjoyment, an extramural education from a very open university.J R HERON (Neurologist, Stoke-on-Trent). 